\title{
LA SOMBRA SOBRE MARVEL: REESCRITURAS DEL HORROR ARQUETÍPICO EN LOS CÓMICS DEL DOCTOR EXTRAÑO
}

\author{
JoRge MARTín \\ Universidad de Salamanca \\ jorgeusal@usal.es
}

Recibido: 13-12-2016

Aceptado: 14-05-2017

\begin{abstract}
(a) (1)
RESUMEN

Desde que H.P. Lovecraft sentó las bases del horror cósmico, otros muchos autores y medios han seguido el influjo de esta manifestación de lo fantástico. Entre ellos, el comic book americano también ha tratado de incorporar a sus códigos los terrores arquetípicos imaginados por el autor de Providence. Nuestro estudio pretende analizar un caso paradigmático: el superhéroe de la editorial Marvel conocido como Doctor Extraño, pues, en ciertos casos, las particularidades de este personaje parecen óptimas para la trasposición de esta visión del fantástico al mundo del cómic.
\end{abstract}

Palabras Clave: Horror arquetípico, Lovecraft, Marvel Comics, reescritura, superhéroe.

\section{Abstract}

Since H.P. Lovecraft laid the foundations of cosmic horror, many other authors and media have followed the influence of this manifestation of the fantastic. Among them, the American comic book has also tried to incorporate into its codes the archetypal terrors imagined by the author from Providence. Our study aims to analyze a paradigmatic case: the superhero of Marvel publishing house known as Doctor Strange, because, in certain cases, the peculiarities of this character seem optimal for the transposition of this vision of the fantastic to the world of comics.

KEY WoRds: Archetypal horror, Lovecraft, Marvel Comics, rewriting, superhero.

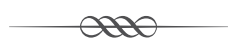




\section{Lo fantástico y Marvel Comics}

El número siete de New Avengers (julio de 2005) de Marvel Comics presenta una reunión muy especial. Con el nombre de Illuminati se reunen algunos de los superhéroes más poderosos de esta editorial. El atlante Namor, el Hombre de Hierro, Reed Richards, el inhumano Rayo Negro, Charles Xavier y el Doctor Extraño conformaban la nómina de los asistentes. Con este grupo, Brian Michael Bendis y Steve Mcniven reflejaron las formas diversas de expresar la fantasía que pueblan el Universo Marvel. Desde un príncipe ligado a la mitología griega, hasta un mutante, pasando por un científico capaz de realizar toda clase de proezas mediante sus inventos; los Illuminati muestran las diferentes maneras empleadas en los comic books de esta editorial para representar lo insólito. El caso del último de los personajes mencionados resulta llamativo, pues una figura como el Doctor Extraño, en su condición de Hechicero Supremo, introdujo ciertas desviaciones de los códigos superheroicos que rigen la mayoría de los productos de dicha editorial.

El Doctor Extraño nació en una historieta breve incluida en el número 110 de Strange Tales (julio de 1963), elaborada por el guionista Stan Lee y el dibujante Steve Ditko. Desde sus comienzos, Extraño introdujo en el imaginario superheroico de Marvel Comics una serie de singularidades que lo separaban del resto de individuos en mallas. Los viajes del hechicero por toda suerte de dimensiones, así como sus enfrentamientos con criaturas ajenas a nuestro plano de la realidad, lo diferenciaban de otros personajes más conectados a los tejados de Nueva York. Este pormenor se reflejaba en los rimbombantes diálogos escritos por Lee, además de en las lisérgicas ilustraciones de Ditko, bastante diferentes a los estándares de la compañía.

Dadas estas circunstancias, nuestro propósito consistirá en examinar el tratamiento en las páginas del Doctor Extraño de otro referente de la fantasía como es el narrador Howard Phillips Lovecraft, pues advertiremos que los rasgos de este personaje se muestran óptimos para incorporar al comic book de Marvel las creaciones del autor de Providence y su círculo. Tras desarrollar un breve apartado teórico, trazaremos una panorámica sobre el mundo de Lovecraft en los cómics de Marvel para, a continuación, centrarnos en la figura de Extraño. En ese punto, realizaremos el análisis de varios ejemplos significativos. 


\section{NOCIONES TEÓRICAS}

Antes de comenzar nuestro estudio, debemos desarrollar unas breves consideraciones teóricas. En primer lugar hemos de aclarar las particularidades de la fantasía lovecraftiana. Uno de sus ejes esenciales tiene que ver con el miedo, en concreto con el horror cósmico o arquetípico, como evolución del terror gótico. Según Rafael Llopis: «En la literatura fantástica, como es lógico, el pobre muerto - en el fondo tan inocente- resultó incapaz por sí solo de torcer el curso del terror real, de desarraigarlo de sus orígenes objetivos» (2001: 16). En cambio, Lovecraft supo manifestar en sus relatos «más que los miedos de su tiempo, los del mismo porvenir (...) Ese terror sin nombre que solo puede expresarse mediante imágenes de sueño o de lectura apocalíptica» (Llopis, 2001: 17).

Para codificar esta sensación de horror, la narrativa lovecraftiana concedía una importancia fundamental a la recepción del mismo. De acuerdo al propio Lovecraft, el relato fantástico debe ser juzgado «no tanto por las intenciones del autor y los mecanismos de la intriga, sino en función de la intensidad emocional que provoca». Por tanto, para el autor de Providence: «Un cuento es fantástico simplemente si el lector experimenta en forma profunda un sentimiento de temor, la presencia de mundos y de potencias insólitos» (Lovecraft, 1984: 16). La culminación de estas ideas dio lugar a los Mythos, una suerte de imaginario de pesadilla concebido por Lovecraft y otros autores, como August Derleth, Robert Ervin Howard, Robert Bloch o Clark Ashton Smith. Este imaginario parte de una premisa establecida por el propio Lovecraft: «Nuestro mundo fue poblado por otras razas que, por practicar la magia negra, perdieron sus conquistas y fueron expulsadas; pero viven aún en el Exterior, dispuestas en todo momento a volver a apoderarse de la Tierra» (Llopis, 2001, 40).

Esta mitología terminaría resultando una gran influencia para toda suerte de manifestaciones de la literatura popular, tanto en el ámbito de la literatura como del cine o el cómic. También la música y el videojuego han experimentado este influjo (Smith, 2006). Debido a que, precisamente, vamos a abordar el influjo de la narrativa lovecraftiana en el comic book superheroico, hemos de añadir a este apartado otras cuestiones teóricas y metodológicas.

Partimos del útil concepto de reescritura, a través de la síntesis del mismo a cargo de José Antonio Pérez Bowie:

Una opción personal mediante la cual el autor se enfrenta a un texto previo y lo somete a una lectura particular en la que proyecta su propio universo subjetivo 
o transmite de modo premeditado o inconsciente las determinaciones del contexto en que se halla inmerso; se trata, pues, de un proceso de apropiación y de revisión consistente en transformar y trasponer, en mirar con nuevos ojos o desde un nuevo contexto un texto precedente (2010: 27-29).

Asimismo, este proceso no tiene por qué partir de una única fuente; al contrario, la tarea de reescritura resuelta susceptible de partir de un conjunto de materiales relacionados: un corpus capaz de generar una reescritura de carácter architextual (Pérez Bowie, 2010: 90).

Nuestra intención consistirá en observar este tipo de fenómenos de trasposición y transformación del imaginario lovecraftiano en otro medio, como es el comic book. Nos hallaríamos, entonces, ante un fenómeno de transficción que puede regirse por diversos factores de carácter espaciotemporal, argumental, interpretativo o estilístico (Gil González, 2012). Dado el cambio de medio, hemos de tener en cuenta los conceptos esbozados por Robert Harvey (1996) y Santos Zunzunegui (2007) sobre la narrativa del cómic y sus convenciones.

\section{LOVECRAFT Y MARVEL COMICS}

Desde sus orígenes, los cómics de la editorial Marvel han incorporado toda clase de contenidos procedentes de la cultura popular. Estos comic books se han nutrido a lo largo de los lustros de un entramado inmenso de referencias que, sin embargo, han logrado conformar un universo autónomo y cohesionado. Este fenómeno ha dado lugar a resultados llamativos. Por ejemplo, en The Mighty Thor, una serie protagonizada por figuras de la mitología nórdica, existe un trasunto de Errol Flynn llamado Fandral que llegó a enfrentarse al dios griego Ares. Asimismo, las corrientes mediáticas imperantes en determinados momentos hallaron su reflejo en las publicaciones de la compañía Marvel. Mientras que el personaje de Luke Cage se erigió como representante gráfico de la blaxploitation, Sang-Chi y Puño de Hierro introdujeron el cine de artes marciales en las viñetas de esta editorial. ${ }^{1}$

El ámbito del terror no podía permanecer ajeno a este proceso de asimi-

1. La monografía de Rafael Marín sobre el imaginario marveliano dedica un espacio interesante a ese respecto (2016: 72-77). Según el autor aludido: «Comunes a nuestra realidad, los cómics del Universo Marvel compartirán con ella nuestra ficción» (Marín, 2016: 72). Sin embargo, esta medida podía resultar complicada, pues como explica Rafael Marín: «El problema que Marvel Comics encuentra al estar ligada a la realidad es que, para no desprenderse de ella, deberá seguir día a día unas modas que, por propia esencia, serán pasajeras» (Marín, 2016: 73). 
lación cultural. Una de las muestras más significativas se encuentra en la colección titulada Tomb of Dracula (1972-1979). La génesis de estos cómics vampíricos resulta interesante, pues nació como fruto de la revisión del Comics Code Authority. Este sistema de autorregulación creado en 1954 imponía severas normas de control de los contenidos que podían aparecer en un cómic. Así, quedaba vedada cualquier alusión a vampiros, zombies u hombres lobo (Nyberg, 1998: 167). Sin embargo, en 1971, la reforma del Comics Code permitió que los horrores procedentes del ámbito de la literatura tuvieran cabida en el comic book (Nyberg, 1998: 172).

Marvel aprovechó esta eventualidad para sacar al mercado una colección inspirada en el personaje de Bram Stoker. Tomb of Dracula inició su andadura en abril de 1972 con un número guionizado por Gerry Conway y dibujado por Gene Colan. La trama de este cómic corrió a cargo del por entonces editor de la compañía Roy Thomas, quien sustituyó en el puesto a Stan Lee. De cara a nuestros intereses, el influjo de Thomas nos resulta fundamental, pues hablamos del guionista responsable de la introducción de Conan en el mundo del cómic americano. Se trata de un autor que, en diversas ocasiones, ha mostrado su interés por trasladar al cómic las creaciones de Robert E. Howard. En definitiva, la irrupción de Drácula en las publicaciones de Marvel se constituye en un ejemplo revelador del fenómeno de reescritura que abordamos, con hitos tan singulares como el Giant-Size Spider-Man \#1 (julio de 1974), donde el vampiro compartió páginas con el mismo Spiderman (Figura 1).

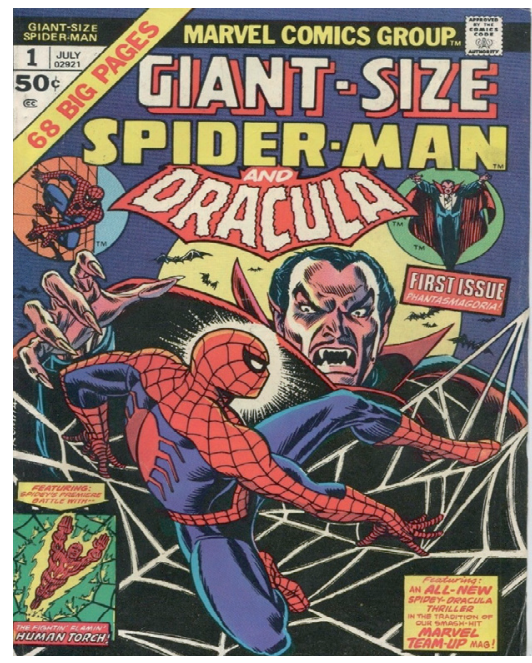

Figura 1. El Hombre araña frente a Dracula (Len Wein y Ross Andru, Giant Size Spiderman \#1, julio de 1974). 
Dadas estas circunstancias, la incorporación del imaginario creado por Howard Phillips Lovecraft al Universo Marvel resultaba esperable. Según Mark Jones (2013), este influjo presentó toda clase de manifestaciones desde los inicios de la editorial americana, especialmente a partir de la década de 1970. El primer eco de las obras del autor de Providence se remonta a finales de la Edad de Oro del cómic americano, periodo situado en las décadas treinta y cuarenta del siglo xx. Se trata tanto del primer cómic de terror publicado por Marvel Comics, llamada entonces Timely Comics, como de la primera translación a dicho medio de un texto de Lovecraft. Nos referimos al número 22 de Amazing Mysteries (febrero de 1949). Este ejemplar contiene una historieta titulada «The Thing at Chugamung Cove!»; en realidad, una trasposición de «The Shadow Over Innsmouth» (1936). Posteriormente, Marvel rescribió otros textos procedentes del circulo lovecraftiano, indicando de manera explícita su origen. Por ejemplo, la colección que dio vida a Thor, Journey into Mistery, trasladó al arte secuencial los relatos «The Haunter of the Dark» (1935) y «The Shadow from the Steeple» (1950), de Lovecraft y Robert Bloch, respectivamente. $^{2}$ Décadas después, Marvel Comics editó la novela gráfica Haunt of Horror: Lovecraft (2008) con guión y lápiz de Richard Corben. Este material recreaba varios relatos y poemas de Lovecraft como «Dagon» (1919) o « The Music of Erich Zann» (1922).

Otros tres casos nos parecen de particular interés, pues parten de otras tantas transficciones fílmicas de contenidos originados por Lovecraft. Las películas Alien (Ridley Scott, 1979), Evil Dead (Sam Raimi, 1981) y The Thing (John Carpenter, 1982) presentan una deuda indudable con el novelista de Providence; a su vez, estos títulos fueron trasladados a los productos de Marvel Comics. ${ }^{3}$ En el número 155 (marzo de 1982) de la colección Uncanny X-Men, los mutantes se enfrentan por primera vez a un trasunto de los xenomorfos de Scott, rebautizados como El Nido (The Nest). Por su parte, la serie limitada Marvel Zombies Vs. Army of the Darkness (de mayo a septiembre de 2007) introducía a Ash Williams y su búsqueda del Necronomicón en el universo de Los Vengadores. Asimismo, el villano Hive, cuya primera aparición se corresponde a Secret Warriors \#2 (mayo de 2009), no parecía muy diferente de la entidad parasitaria presente en la película de Carpenter.

Con todo, dadas las peculiaridades del personaje, el Doctor Extraño se

2. En concreto, nos referimos a los números 4 y 5 de Journey into Mistery, publicados en abril y junio de 1973.

3. Recomendamos la monografía de Charles Mitchell (2001) sobre las reescrituras fílmicas de la obra de Lovecraft, entre ellas las tres películas aludidas en el texto. 
ha configurado como un candidato idóneo para alojar en sus páginas referencias lovecraftianas de toda índole. Desde los inicios del mago en Marvel Comics, las conexiones con el architexto lovecraftiano han resultado múltiples y diversas. La propia colección que dio vida a Strange, Strange Tales, coincide en su nombre con aquella publicación pulp que trató de competir en su día con Weird Tales. La revista Strange Tales (1931-1933) albergó textos de miembros distinguidos del círculo de Lovecraft como Robert E. Howard o Clark Ashton $S_{\text {Smith }}^{4}$. Por su parte, la versión homónima de Marvel Comics comenzó su andadura dedicada a la historieta de terror, intentando emular el éxito en dicho ámbito de Entertaining Comics. ${ }^{5}$

Cuando en el número 110 de la versión Marvel de Strange Tales aparezca el Doctor Extraño, sus vínculos con el mundo de la magia y su versión superheroica de las artes místicas pueden retrotraernos al mundo ideado por Lovecraft. La misma palabrería pseudoesotérica — «Por las Eternas Huestes de Hoggoth»- que Stan Lee ponía en boca del mago Stephen Strange parece extraída de los grimorios imaginados por Lovecraft. Algunos de los villanos de Extraño, como Pesadilla o Dormammu, se asemejan a las entidades cósmicas de los Mythos. De igual modo, la alusión continúa a enigmáticos y ficticios volúmenes como el Libro de los Visanthi o el Rollo de la eternidad nos recuerda a la cita de ejemplares inventados por Lovecraft y su círculo. ${ }^{6}$

La incorporación a las viñetas protagonizadas por Strange de equipos creativos relacionados con el mundo del terror añadió a estos cómics un tono más oscuro y, además, la asimilación de mayores referencias lovecraftianas. Una muestra interesante, que puede servirnos de avance de nuestro estudio, se halla en el Doctor Strange \# 183 (noviembre de 1969). ${ }^{7}$

Este comic book, titulado «They Walk by Night!» es responsabilidad de dos artistas ya aludidos: el guionista Roy Thomas y el dibujante Gene Colan. La primera página de dicho relato se constituye en una declaración de intenciones, al incluir la cita siguiente en una cartela: «Vivimos en una plácida isla

4. Según Robert Michael Cotter: «Strange Tales was clone of Weird Tales clone in every aspect, except one: it actually paid its authors in time» (Cotter, 2008: 149).

5. La misma editorial EC publicó varias historias de clara inspiración lovecraftiana, tratando de sortear cualquier posible violación de derechos de autor. Por ejemplo, el número 16 (diciembre de 1950) de Vault of Horror recogía una traslación de los relatos de Lovecraft titulados «In the Vault» (1925) y «Cool Air» (1929). Acerca de esta compañía ligada al mundo del terror, véase Geissman (2005).

6. En http://www.marvunapp.com/Appendix4/tomes_of_eldritch_knowledge.htm (6/12/2016), Jeff Christiansen enumera todos aquellos libros ficticios aparecidos en el Universo Marvel. Algunos, como el Necronomicón o el Libro de Eibon, proceden de forma directa del círculo lovecraftiano.

7. En este caso, para facilitar la lectura y debido a que no se trata de nuestro objeto de estudio principal, vamos a emplear la edición española publicada por Forum (marzo de 2000) dentro del tomo Los Defensores: El nacimiento de los Defensores. 
de la ignorancia en medio de un negro océano de infinitud y no conviene que nos aventuremos muy lejos. H. P. Lovecraft (1890-1937)» (Los Defensores, 2000: 1). Se trata de un fragmento perteneciente a «The Call of Cthulhu» (1928) que preludia los vínculos con el horror cósmico incluidos en la historieta escrita por Thomas. La trama parte de un telegrama recibido por Stephen Strange, donde un tal Kenneth Ward -acaso un guiño al personaje lovecraftiano Charles Dexter Ward - le escribe pidiendo ayuda. Al llegar a su encuentro, el Doctor Extraño encuentra a Ward en un estado cercano a la catatonia. Por medio de sus encantamientos, Extraño logra que Ward le indique las circunstancias de su demanda.

La analepsis narrada por Ward se enmarca en «en un solitario valle en las montañas del Himalaya» (Los Defensores, 2000: 14). Mediante globos de texto, el personaje realiza una serie de precisiones que, en el fondo, se dirigen tanto al narratario de su relato como a los destinatarios del cómic. La retórica empleada parece emular el usus scribendi del autor de Providence: «¡Aquí está...tal como me mostró mi fantástico sueño! ¡Tal como de algún modo yo sabía que sería! ¡Extrañas formas geométricas esculpidas por alguna inhumana civilización!» (Los Defensores, 2000: 14).

En primer lugar, el motivo del sueño alberga una marcada importancia en «The Call of Cthulhu», sobre todo, en el caso del personaje llamado Henry Anthony Wilcox, que vislumbró ciudades insólitas. No será el único relato en que Lovecraft se sirva del sueño como impulsor de sus tramas. Para Timo Airaksinen los sueños resultan fundamentales para comprender la narrativa lovecraftiana; si bien, considera complejo precisar la causa de este fenómeno en su conjunto. Acaso, este proceso tendría que ver con el modo en que los personajes encaran el horror, de manera semejante a cuando nos enfrentamos a los terrores en las pesadillas. Airaksinen sostiene que en nuestras fantasías oníricas «We are absolutely alone, which may partly explain why Lovecraft wants to use dreams as a road to horror» $(1999,204){ }^{8}$

De vuelta al cómic de Thomas y Colan, Ward contempla espantado el extraño emplazamiento que había formado parte de sus sueños. Sus palabras para describir el enclave presentan unas adjetivaciones que nos acercan a la prosa de Lovecraft. Asimismo, las referencias a una suerte de formas alejada de los patrones conocidos se asemejan a las alusiones sobre la geometría no euclidiana que caracteriza a la ciudad de R'lyeh. Destacamos los esfuerzos a

8. Recomendamos al respecto la consulta del análisis elaborado por Noel Carrol (1990: 159-195) sobre las bases de la ficción de terror y sus conexiones con las pesadillas. 
los lápices por parte de Colan para esbozar unas figuras que resulten inusuales (Figura 2). En este caso, hallamos una desviación respecto a la fuente y un nuevo modo de plasmar el horror arquetípico. Como apuntó David Roas, respecto a la expresión de este horror: «Lo fantástico narra acontecimientos que sobrepasan nuestro marco de referencia, es por tanto la expresión de lo innombrable, lo que supone una dislocación del discurso racional: el narrador se ve obligado a combinar de forma insólita nombres y adjetivos» (Roas, 2001: 29). Aquí, la enunciación verbal se ajusta a ese patrón, pero se ve completada por unos signos de tipo icónico.

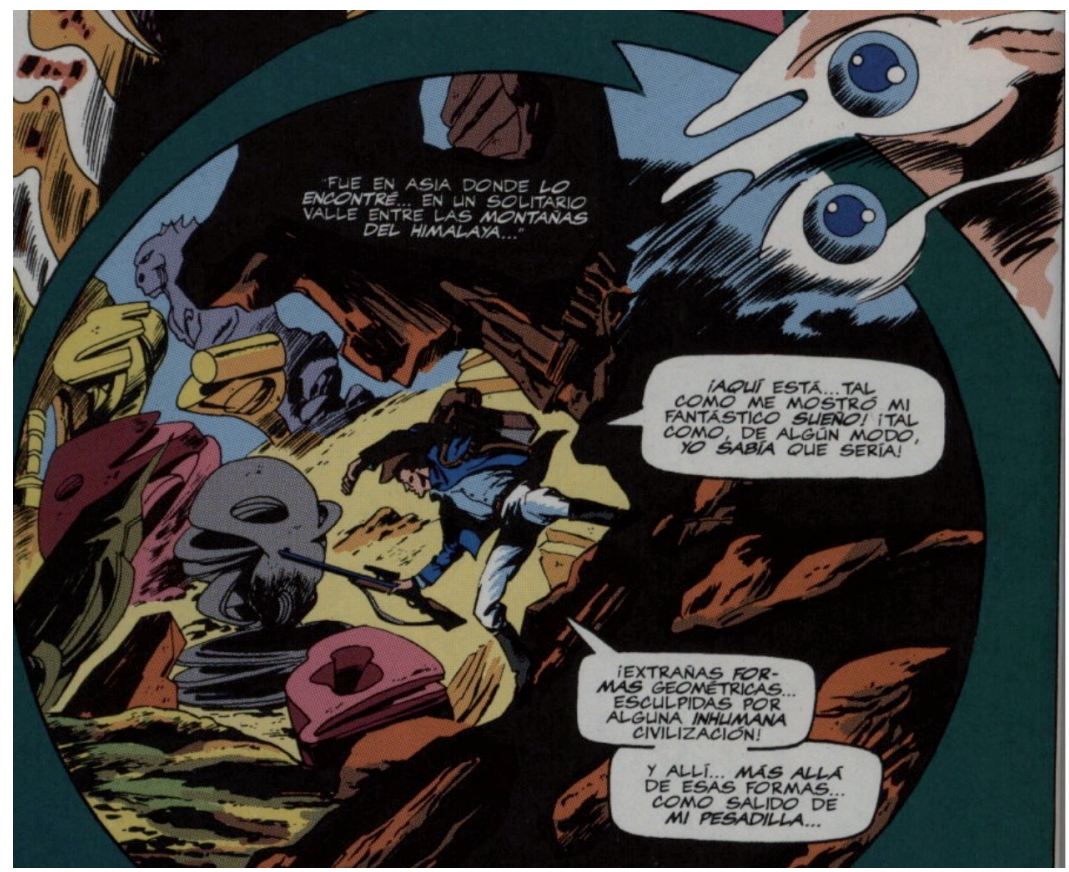

Figura 2. La geometría no euclidiana de los Mythos

(Roy Thomas y Gene Colan, Doctor Strange \# 183, noviembre de 1969)

Al fin, el personaje nombrado topa con unas estatuas «grotescamente esculpidas» que, según Ward, «esperan, callada y pacientemente el momento en que vuelvan a cobrar vida» (Los Defensores, 2000: 14). Igual que en las narraciones de los Mythos, observamos unos seres en estado latente que aguardan su despertar. Con este breve análisis pretendíamos mostrar una suerte de prolegómeno, e incluso de precedente, de la historia que vamos a examinar con mayor profundidad a continuación. Comprobaremos cómo 
ciertos recursos y tópicos, que trataremos a partir de aquí, ya se encontraban en este número de Doctor Strange.

\section{Marvel Premiere y Lovecraft}

Muchos y multiformes son los oscuros horrores que infestan la Tierra desde sus orígenes.

Abdul Alhazred, El Necronomicón.

Nos disponemos a rastrear el influjo lovecraftiano en el relato conformado por los volúmenes 4 a 10 de la colección Marvel Premiere, material publicado entre septiembre de 1972 y septiembre de 1973. Para empezar hemos de contar con la naturaleza de esta serie de Marvel Comics, que abarcó 61 ejemplares desde 1972 hasta 1981. Esta colección permitía desarrollar historias protagonizadas por nuevos personajes, además de relanzar otros que no habían alcanzado un éxito notable en sus series regulares. En lo referente al primer caso, Marvel Premiere sirvió para introducir en el Universo Marvel a superhéroes como Puño de Hierro o la segunda encarnación del Hombre Hormiga. Respecto al segundo pormenor, personajes como el Doctor Extraño tratarán de revitalizar sus aventuras tras una trayectoria irregular dentro de sus propios títulos.

A su vez, los siete números que pretendemos revisar buscaron incorporar al imaginario de Marvel un nuevo villano llamado Shuma-Gorath. Este asunto presenta de por sí un interés destacable. Al cabo, esta entidad fue creada por Robert E. Howard en su relato conocido como «The Curse of the Golden Skull» (1928), como una suerte de trasunto del lovecraftiano Shub-Niggurath. ${ }^{9}$ Más tarde, Marvel, con Roy Thomas como editor, adquirió los derechos para explotar las creaciones de Howard. Esta decisión resultó muy provechosa para dicha compañía; según explicó Don Herron: «The largest success they had was Conan the Barbarian four colour comic, originally written by Thomas and drawn by Barry Smith. For a year of two, this magazine was the most popular comic book in the world, judging from sales figures» (Herron, 2000: 175).

En consecuencia, al alcanzar la colección Conan the Barbarian el número 37 (abril de 1974), Roy Thomas, junto al dibujante Neil Adams, se inspiró en el cuento de Howard citado antes para articular una historieta con el mismo

9. Esta narración de Howard se publicó por vez primera en el número 9 de Howard Collector (1969). 
nombre. Ahora bien, la presentación de esta criatura con aspecto de pulpo se produjo en el arco argumental desarrollado en los volúmenes 4 a 10 de Marvel Premiere. En términos generales, la trama se concibe como el plan de Shuma-Gorah para regresar a nuestra dimensión. Como paso previo, esta entidad enfrentará de manera sucesiva al Doctor Extraño con otras criaturas a su servicio de claras reminiscencias lovecraftianas, como Sligguth, N'Gabthoth, Dagoth o Kathulos.

No centraremos fundamentalmente en el estudio del cuarto número de Marvel Premiere que abre este arco. La razón principal de esta resolución consiste en que este cómic presenta una serie de rasgos significativos; entre ellos, que puede considerarse una curiosa reescritura de « The Shadow Over Innsmouth» de Lovecraft. Como punto de partida, hemos de dedicar un breve espacio al equipo creativo responsable de dicho volumen titulado «The Spawn of Sligguth». En primer lugar, destacamos la presencia del ya mencionado Roy Thomas. Este autor aparece en los créditos bajo las funciones de editor y creador del argumento del relato. En este punto, hemos de considerar el llamado método Marvel, sistema establecido por Stan Lee para generar los cómics de esta compañía. El ilustrador Steve Ditko describió este proceso creativo:

Stan [Lee] provided the plot ideas. There would be a discussion to clear up anything, consider options and so forth. I would then do the panel/page breakdowns, pencil the visual story continuity, and, on a separate paper, provide a very rough panel dialogue, merely as a guide for Stan. We would go over the penciled story/art pages and I would explain any deviations, changes, and additions, noting anything to be corrected before or during the inking. Stan would provide the finished dialogue, for the characters, ideas, consistency and continuity. Once lettered, I would ink the pages (Raphael y Spurgeon, 2003: 91).

Este patrón concedía una importancia destacada al trabajo de los dibujantes, hecho que, en ocasiones, ocasionaba que la labor del guionista pudiera «redundar con el texto lo ya claramente apreciable solo con ver el dibujo» (Marín, 2016: 162). Justamente, Rafael Marín pone como ejemplo de dicho fenómeno los trabajos de Roy Thomas, cuyos diálogos resultaban reiterativos respecto al apartado icónico del cómic en cuestión. Si bien, también es cierto que este guionista destacaba por la locuacidad de sus diálogos. ${ }^{10}$

En el caso que nos ocupa, hallamos a Thomas como encargado de ela-

10. Pierre Comtois vincula la característica verbosidad de Thomas al influjo ejercido por su bagaje cultural. Sobre todo, este autor apunta a la inclinación de Thomas por el cine clásico, que, además, empezaba a televisarse por aquel entonces (Comtois, 2011: 20). 
borar la trama base del Marvel Premiere \#4. Otra de las cartelas de la primera página contiene una leyenda reveladora: «Featuring concepts created by Robert E. Howard» (Marvel Premiere \#4, 1972: 2). Por consiguiente, observamos cómo la tarea de Thomas como editor y creador del argumento parte de un material que él mismo ya manejó en la serie de Conan en calidad de guionista. Aquí, además del responsable de la trama o plot, encontramos acreditado otro guionista encargado de los diálogos. Se trata de Archie Goodwin, escritor ligado en sus comienzos a la revista de terror Creepy de la editorial Warren. Precisamente, en dicha publicación Goodwin guionizó una interesante combinación de varios relatos ligados a los Mythos. En concreto, esta historieta mezclaba «Fane of the Black Pharaoph» (1937), «The Shambler from the Stars» (1935) y «The Skull of the Marquis de Sade» (1965), de Robert Bloch. ${ }^{11}$

Por último, se encargó de los lápices otra figura cuyos trabajos muestran conexiones con el Círculo de Lovecraft: Barry Smith. Este dibujante no solo se encargó de ilustrar las viñetas basadas en los textos de Howard para Conan the Barbarian, sino que trabajó posteriormente en varios ejemplares de la colección de Marvel Comics conocida como Tower of Shadows (1969-1975), una serie dedicada a la historieta de terror.

Ahora bien, Smith dejó el Marvel Premiere \#4 inconcluso, por lo que Roy Thomas decidió encargarle a Frank Brunner que terminara los bocetos a lápiz restantes, además de entintar dicho cómic. Brunner también había ilustrado cómics dentro del ámbito del terror para publicaciones como Creepy o Vampirella. ${ }^{12}$ En principio, Frank Brunner no parecía muy convencido de dibujar material relacionado con el mundo superheroico, además de que los plazos para completar dicho número resultaban excesivamente justos. Sin embargo, el artista accedió finalmente a ilustrar el cuarto número de Marvel Premiere

11. El título original del cómic de Goodwin era «Collector's Edition» y apareció por vez primera en el Creeppy \#10. A los lápices se encontraba Steve Ditko, el creador gráfico del Doctor Extraño. Acerca de las publicaciones de la editorial Warren nos remitimos al estudio de David Roach y Jon Cooke (2001). 12. En una entrevista, Brunner aclaró las circunstancias de su llegada a Marvel Premiere: «I did an issue of Marvel Premiere \#4. I was finishing off a story that Barry Windsor-Smith had started. Smith got sick or something, and basically he did the first five pages, and I was sticking to his layouts, and completed that book, penciled and inks. Archie Goodwin wrote it». Según Brunner, Roy Thomas le convenció comentando lo siguiente: «you [Brunner] do great monsters, we're doing Dr. Strange with a Lovecraft motif, where he's battling various monsters. Would you like to do the book?». La entrevista en http://twomorrows.com/comicbookartist/articles/06brunner.html (6/12/2016). Como muestra de un trabajo posterior de Brunner ligado al mundo de Lovecraft, podemos mencionar su labor como portadista para el one-shot titulado H.P. Lovecraft's The Return of Cthulhu, editado por Cross Plains (julio del 2000). El guion de este cómic corrió a cargo de una figura ya familiar en estas páginas: Roy Thomas 
debido, en buena medida, a sus conexiones con el ámbito del terror. ${ }^{13}$ En suma, nos vemos con un equipo que no solo presentaba una serie de experiencias en el ámbito del cómic de horror, en términos generales, sino que mantuvo conexiones diversas con el universo originado por el círculo de Lovecraft.

Junto a los créditos y al título, «The Spawn of Sligguth» parte de un cuadro de apoyo basado en el mismo recurso que observamos en el Doctor Strange \#183. Esta cartela reza: "Some gods die, others but slumber, and in their dreaming wait for a dawning hour and movers prime, and the opening of a gate! The Thanatosian Tomes, from a 1623 translation by the Marquis of Rais» (Marvel Premiere \#4, 1972: 2). El elemento extradiegético anotado sirve para orientar desde un principio al destinatario acerca de las fuentes textuales de la historia. Asimismo, la trama creada por Thomas participa del consabido recurso de Lovecraft de servirse de referencias pseudointertextuales.

Según explicó Rafael Llopis, este mecanismo empleado por el autor de Providence consistía en la alusión combinada de volúmenes reales con títulos rimbombantes, capaces de impresionar a los lectores, con otros ejemplares ficticios que ayudaban a configurar el imaginario presente en los Mythos (Llopis, 2001: 50). En el cuarto número de Marvel Premiere, este proceso sirve también para informar al lector avezado acerca del influjo literario que va a caracterizar a las viñetas subsiguientes.

Observamos cómo este cuadro de apoyo trata de remedar la retórica ocultista de los falsos tomos ideados por el Círculo de Lovecraft. Las menciones a unos antiguos dioses inertes, que esperan su despertar, son frecuentes en este tipo de referencias pseudointertextuales. También, como en la fuente literaria, los datos añadidos se conforman como un medio para sumar verismo a la falsa cita y, a la vez, un componente irónico, en este caso con la insinuación de que el posible autor de Los libros de Thanathos pudiera identificarse con Guilles de Rais.

Posteriormente, el cómic dibujado por Smith y Brunner volverá a acudir a este recurso, en este caso por medio de un homenaje aun más claro. El personaje clásico de las aventuras del Doctor Extraño conocido como El Anciano (The Ancient One) advierte a Strange acerca del contenido de unos volúmenes que tratan sobre «a cosmic obscenity that slumbers!» (Marvel Premiere \#4, 1972: 11). En concreto, menciona Los pergaminos del Mar Negro y Los cultos innombrables, de Von Juntz. Si el primero de los títulos citados parece un

13. Junto a la entrevista citada en la nora anterior, recomendamos la consulta del apartado dedicado a la génesis del Marvel Premiere \#4 incluido en la monografía de Pierre Comtois (2011: 107-108) sobre los cómics de la Marvel durante la década de los setenta. 
trasunto de los rollos del Mar Muerto, el segundo de los volúmenes ficticios procede del texto de Howard llamado «The children of the night» (1931). ${ }^{14}$

De vuelta a la primera página del cómic que nos ocupa, hemos de realizar una breve mención a la puesta en imagen de la misma (Figura 3). Se trata de una viñeta a toda página que trata de impactar a los destinatarios con una única escena como punto de partida de la historieta que se desarrollará posteriormente. Destacamos dos aspectos de interés. En primer lugar, el uso del fuera de campo, que muestra a un Strange perturbado por una amenaza que no podemos observar, excepto por la sombra que proyecta. Asimismo, las tareas de Brunner como entintador refuerzan esa sensación de intriga por medio del uso del claroscuro.

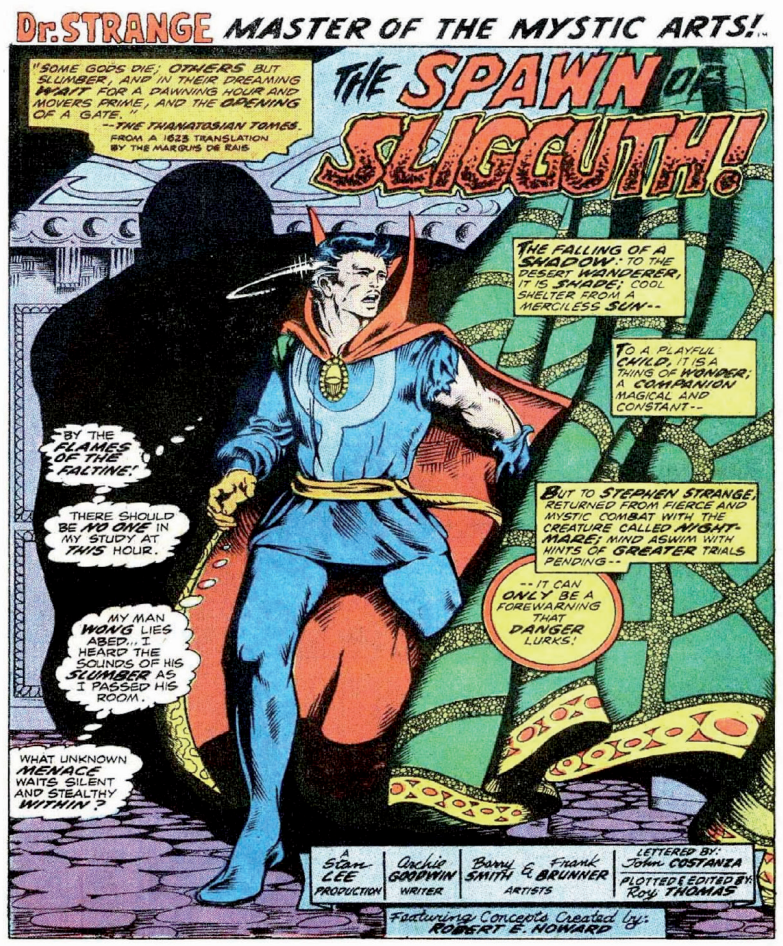

Figura 3. La splash page que abre el Marvel Premiere \#4 (Archie Goodwin, Roy Thomas, Barry Smith y Frank Brunner, Marvel Premiere \#4, septiembre de 1972).

14. Lin Carter (2001: 107-147) redactó un interesante estudio de los libros ficticios creados por el círculo de Lovecraft para sustentar su mitología del horror cósmico. En el caso de Los cultos innombrables, Carter señala que se trata de «Howard's greatest addition to the Mythos» (2001: 142). La configuración final del título de este grimorio ficticio partió de Lovecraft, quien sugirió a Howard que sustituyera el título en inglés, Nameless cults, por una versión en alemán más impactante. Aquí entró en juego August Derleth, que sugirió su forma definitiva: Unauspressprechlichen Kulten (Carter, 2001: 142). 
En lo referente a otros elementos narrativos, una voz heterodiegética se manifiesta en varias cartelas de apoyo para subrayar lo que una simple sombra puede suponer para alguien como Strange: «It can only be a forewarning that danger lurks!» (Marvel Premiere \#4, 1972: 2). Llamamos la atención hacia el uso de la oración exclamativa, frecuente en todo el número. Se trata de un elemento, tan lingüístico como paralingüístico, destinado a subrayar de forma efectista los motivos tratados a lo largo del cómic, común en el género durante el periodo que nos ocupa.

Al fin, Extraño descubre la identidad del visitante misterioso de su Sancta Santorum, un individuo llamado Ethan Stoddar, quien necesita de forma desesperada la ayuda del mago. Como en el número 183 de Doctor Strange, Thomas vuelve a acudir al mismo motivo para impulsar la trama: Extraño debe socorrer a una persona que ha topado con el horror. Este recurso va a erigirse como fundamental para incorporar el terror a un cómic que procede del mundo superheroico. Frente a un personaje como Strange, habituado a enfrentarse a lo imposible, encontramos otras figuras ajenas a ese mundo, por lo cual se convierten en candidatos susceptibles de experimentar el horror. Recordemos las nociones expuestas previamente acerca de la importancia del receptor dentro del relato para constituir la sensación de horror.

Finalmente, Extraño accede a escuchar a Ethan Stoddar; en este momento, el cómic combina los globos de texto vinculados al relato de Stoddar con los pensamientos de Strange. Este último se muestra marcado por la preocupación, interrogándose acerca de si este acontecimiento preludia «some dangerous plot» (Marvel Premiere \#4, 1972: 3). En cuanto a la narración de Stoddar, advertimos ciertos componentes ligados al terror de índole lovecraftiano. Para empezar, la voz heterodiegética dentro de una cartela nos advierte de las sensaciones de Stoddar, expresadas «by eyes haunted by nothing less than true fear» (Marvel Premiere \#4, 1972: 4). Esta reacción se ajusta con el relato de Stoddar incluido en los globos de texto correspondientes.

Este personaje revela su preocupación por el estado de su novia Beth, de quien no sabe nada desde hace tres semanas. Esta acudió a la población ficticia de Nueva Inglaterra llamada Starkesboro para trabajar en su tesis sobre el ocultismo en América. En la biblioteca de dicha localidad, Beth consultó «a lot of weird books» que no había en ningún otro sitio, como Thanatosian Tomes (Marvel Premiere \#4, 1972: 4). A partir de entonces, Beth reflejó de forma poco coherente «freaky stuff about dark gods, forbidden cults...» (Marvel Premiere \#4, 1972: 4). Todo ello, hasta que interrumpió su correspondencia con Stoddar. 
La reacción aterrorizada de Stoddar, la inclusión de un intercambio de tipo epistolar y las investigaciones librescas que conducen a un mundo siniestro no pueden sino retrotraernos al imaginario lovecraftiano. Con el propósito de acentuar el componente terrorífico del relato de Stoddar, el trabajo de Smith y Brunner presenta en una tira de cuatro viñetas, con otros tantos primeros planos del personaje, su expresión de temor, que contrasta con el negro de los fondos. Al cabo, el Doctor Extraño decide socorrer a Stoddar sirviéndose del objeto conocido como Ojo de Agamotto. Esta reliquia dotada de facultades místicas le permite a Strange certificar la veracidad del testimonio de su visitante e, incluso, advertir la envergadura de sus sentimientos de terror. Así, observamos de nuevo la confrontación entre un personaje inmerso en una realidad marcada por la maravilla, capaz de enfrentarse a lo imposible, frente a un individuo como Stoddar perplejo ante esas circunstancias.

Entonces, Extraño decide acompañar a Stoddar a Starkesboro para buscar a Beth. En este punto, el cómic va a presentar unas coincidencias estructurales y temáticas notables con «The Shadow Over Innsmouth». En primer lugar, el propio motivo del viaje resulta fundamental dentro del relato de Lovecraft mencionado. Según Alberto Santos Castillo: «El tema no es casual pues Lovecraft fue un apasionado de los viajes» (2016). En lo referente al cuento lovecraftiano, este motivo va a configurarse como «un camino iniciático hacia el terror» (Santos Castillo, 2016) y así también ocurre en el Marvel Premiere \#4: Strange y Stoddar se dirigen, igual que el protagonista del relato de Lovecraft, en autobús hacia la misteriosa localidad donde toparán con el horror.

Sin embargo, hallamos una particularidad de relevancia. Durante una pausa para almorzar, Strange y su acompañante mantienen una conversación de interés. Stoddar informa al hechicero acerca de las particularidades de Starkesboro, un enclave caracterizado por su aislamiento y por albergar una población cerrada y xenófoba que, además, «descended from the same bunch of people» (Marvel Premiere \#4, 1972: 7). Al parecer, estos individuos proceden de «some obscure religious sect», que llegó a Nueva Inglaterra en el siglo xviI (Marvel Premiere \#4, 1972: 7). Según estudió Bernd Steiner (2005: 32), uno de los componentes esenciales de la fantasía lovecraftiana tiene que ver con el empleo de entornos espaciales marcados por la endogamia y la decadencia, convertidos en marcos adecuados para situar las experiencias del horror arquetípico. Así ocurre en relatos como «The Dunwich Horror» (1929) o «The Shadow Over Innsmouth» (1936).

En este punto, el cómic de Marvel introduce un mecanismo que va a 
subvertir la cita lovecraftiana: el humor. Stoddar le reprocha a Strange que no parece prestar mucha atención a sus explicaciones; entonces, el hechicero responde del modo siguiente: «I confess that having grown used to dealing with cosmic mysteries (...) I'd forgotten what simple and subtle delight there could be in consuming an ordinary hot dog», Marvel Premiere \#4, 1972: 7). Tal como aclaró Rafael Marín: «El humor Marvel será un tipo de humor real y cotidiano que ganará precisamente por desenvolverse en unos tipos y unas situaciones que sobrepasan con mucho los límites de lo normal» (2016: 85).

En el caso que nos ocupa, la actitud imperturbable de Extraño y la referencia al perrito caliente, en una charla que incorpora enunciados como «misterios cósmicos», contribuye a articular el efecto humorístico. Justamente, este distanciamiento por el humor va a constituir una de las mayores divergencias entre la fantasía de horror lovecraftiana y el relato superheroico de Marvel. De nuevo, observamos la amplia diferencia entre un personaje como Extraño, un superhéroe habituado a lidiar con lo insólito, y el horror experimentado por Stoddar.

Más tarde, los protagonistas siguen su camino de forma que el comic book se acerca a la estructura planteada por el narrador de Providence para «The Shadow Over Innsmouth». Strange y Stoddar continúan el viaje durante la noche en un autobús prácticamente vacío, hasta que el mago advierte en el horizonte, de forma similar al personaje del texto de Lovecraft, «gabled roofs, the hint of shadowed steeples» (Marvel Premiere \#4,1972: 7). Al llegar, al igual que en la narración de Howard Phillips Lovecraft, los personajes bajan del autobús en la plaza del pueblo, donde son recibidos por el sonido de las campanas de la iglesia de Starkesboro, que repiquetean a altas horas de la noche. Asimismo, el Doctor Extraño y su compañero se instalan en el único y destartalado hotel de esta localidad.

Desde su habitación, Strange se sorprende, al igual que le sucedió al protagonista de «The Shadow Over Innsmouth», tanto de lo insólito del momento para efectuar una ceremonia en la iglesia, como del aspecto de los habitantes de Starkesboro allí reunidos, caracterizados por unos rasgos demasiado similares. ${ }^{15}$ Aquí, frente a una primera descripción con cierto detalle de los habitantes de Innsmouth presente en el relato de Lovecraft, ${ }^{16}$ el cómic pre-

15. Por su parte, al protagonista del relato de Lovecraft le sorprende algo sobre los primeros habitantes de Innsmouth con los que topa: «Casi todos tenían los mismos rasgos faciales y los mismos gestos, cosa que producía una repugnancia instintiva e irremediable» (Lovecraft, 2001: 240).

16. «Algunos tienen la cabeza estrecha y rara, con la nariz chata y aplastada; y tienen también unos ojos fijos que parece que nunca parpadean, y una piel que no es como la piel normal que tenemos los demás; es áspera y costrosa, y a los lados del cuello la tienen arrugada o como replegada» (Lovecraft, 2001: 227). 
fiere reservar la intriga. La viñeta donde se menciona por primera vez el aspecto de los pobladores de Starkesboro se presenta en un plano picado lejano, que apenas deja ver los rasgos de estos. Solo los globos de pensamiento nos informan de las impresiones de Extraño acerca de dichos individuos.

Entonces, la trama ideada por Roy Thomas se desvía del curso de los acontecimientos que acercaban al comic book de la narración redactada por Lovecraft. Mediante su proyección astral, Stephen Strange decide encontrarse con El Anciano, que le advierte del peligro al que se enfrenta. A través de variaciones como esta, el material contenido en el Marvel Premiere \#4 no termina de cortar sus lazos con la fantasía superheroica, además de manifestar que este comic book se concibe como parte de una saga, que se desarrollará en los números siguientes. Con todo, el guion de Goodwin acude a un recurso óptimo para contrarrestar este pormenor y ayudar al efecto de terror buscado: Extraño percibe que el ambiente de Starkesboro está disminuyendo sus facultades mágicas.

Al día siguiente, Extraño y Stoddar deciden explorar el pueblo en busca de Beth. En un momento dado, Stoddar encuentra a un viejo conocido cuyo aspecto tan cambiado le extraña sobremanera. Este último afirma que sus facciones se corresponden con las propias de los habitantes de Starkesboro, y proclama orgulloso que a diferencia de Stoddar, su padre «didn't have the airs yours did marryn' outside Starkesboro!» (Marvel Premiere \#4, 1972: 12). La viñeta que contiene estas declaraciones se concibe en forma de un primer plano donde Smith y Brunner tratan de destacar los rasgos repugnantes de este individuo, sin llegar al efectismo desmesurado, pero acercándose a las indicaciones presentes en la fuente lovecraftiana, al intentar emular la piel costrosa que caracteriza a los habitantes de Innsmouth.

En el imaginario lovecraftiano, el horror cósmico suele manifestarse en forma de la apariencia abyecta de las criaturas híbridas que rondan algunos de los relatos del narrador de Nueva Inglaterra. Aunque en última instancia, estos engendros semihumanos alcanzan su aspecto monstruoso por medio de un factor externo, el punto de partida se corresponde con una situación marcada por la endogamia y la decadencia. Esta eventualidad resulta determinante para llegar a las aberraciones híbridas, conocidas como profundos, que pueblan Innsmouth. ${ }^{17} \mathrm{El}$ cómic ilustrado por Smith y Brunner parece emular

17. Junto al trabajo ya citado de Bernd Steiner (2005), recomendamos la consulta del estudio elaborado por Faye Ringel (2014) sobre el tratamiento del espacio de Nueva Inglaterra en la narrativa de Lovecraft. Dentro de este ensayo, el examen de las ideas de dicho autor sobre los conceptos relacionados de decadencia y mestizaje resultan fundamentales. Para Ringel: «Lovecraft believed in reverse evolution, racial decadence which could be caused by too much imbreeding or by indiscriminate mongrelization» (2014). 
dicho proceso, como indica el personaje de Stoddar: «The Starkesboro look... get worse with age» (Marvel Premiere \#4, 1972: 12).

Después del encuentro referido, Extraño y Stoddar se separan para inspeccionar respectivamente la iglesia y la biblioteca del enclave ficticio situado en Massachusetts. Esta decisión presenta implicaciones narrativas de interés, pues permite mostrar la experimentación del horror por parte de los personajes de dos modos distintos. En un primer momento, el foco se centra en Stoddar, que parece advertir la presencia de Beth. La composición de las viñetas alterna planos semisubjetivos desde la espalda de dicho personaje, con otro subjetivo centrado en la figura de Beth vuelta de espaldas. Este tipo de focalización ayuda a crear el efecto de tensión e intriga. Junto a este recurso se añade otro: una elipsis que suspende la acción centrada en Stoddar. En consecuencia, el cómic vuelve de nuevo a dirigir su atención hacia el Doctor Extraño, que se encuentra frente al altar de la iglesia de Starkesboro. Ahora, la sensación de horror no se busca por medio de la puesta en imagen de los elementos de las viñetas, sino a través de los globos de texto. Es verdad, que los lápices de Smith y Brunner tratan de impresionar a los receptores gracias al claroscuro y a la representación del siniestro altar de la iglesia, con una gran cruz invertida rodeada por una serpiente. Sin embargo, el mayor protagonismo de estas viñetas se halla en los diálogos introducidos por Archie Goodwin.

En páginas anteriores, comentamos cómo las particularidades del llamado método Marvel solían traer consigo un uso redundante de los globos de texto. Ahora encontramos un fenómeno semejante, con Extraño refiriendo una serie de elementos visibles por los lectores del cómic. Ahora bien, las intervenciones incorporadas por Goodwin buscan, de igual modo, alcanzar el efecto de horror producido por ese siniestro altar. Strange comenta las sensaciones que le suscita dicho lugar a través de unos recursos retóricos que pueden recordarnos los mecanismos lingüísticos empleados en los relatos sobre el horror cósmico. Así, las palabras de Strange incluyen adjetivaciones efectistas, por ejemplo: «grim and ominous» o «dark deep stains». También encontramos exclamaciones destinadas a recalcar el espanto experimentado por Extraño, como «Shades of the Seraphim!». Asimismo, observamos la alusión a «the most sinister of occult tomes», además de la referencia a Valusia, enclave ficticio imaginado por Robert E. Howard (Marvel Premiere \#4, 1972: 14).

De nuevo, la acción queda en suspenso para volver a Stoddar. Ahora, la puesta en imagen de las viñetas vuelve a erigirse en el medio más importante elegido para propiciar el efecto de horror. Con una planificación que puede recordarnos a la presentación del cadáver de la madre de Norman Bates en 
Psycho (Alfred Hitchcock, 1960), la secuencia de acontecimientos llega hasta la imagen impactante en primer plano de Beth, quien muestra los mismos rasgos inhumanos que el habitante de Starkesboro revisado arriba (Figura 4). ${ }^{18}$

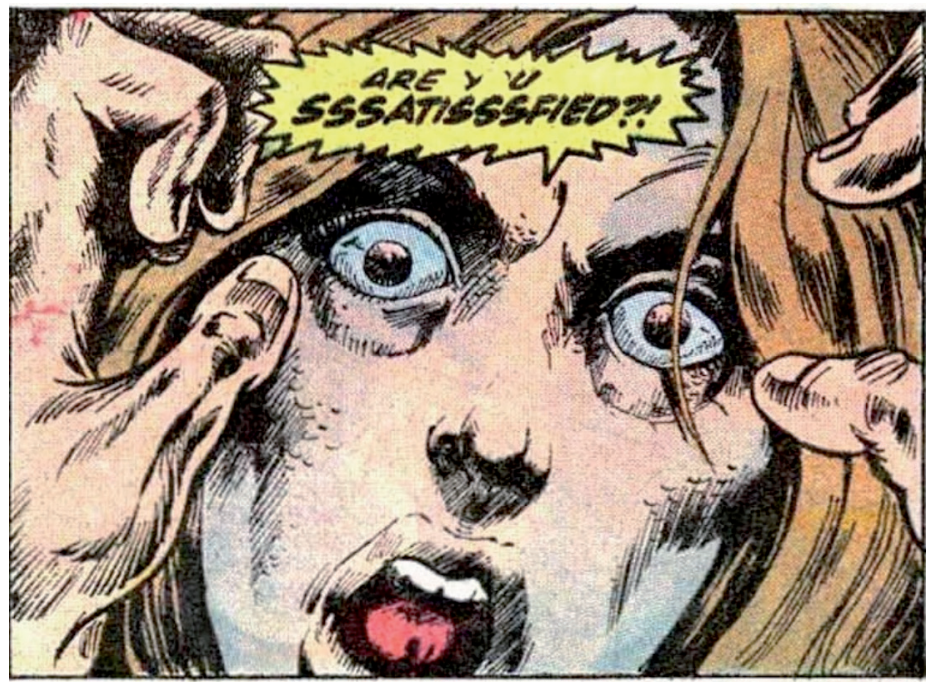

Figura 4. La presentación del aspecto aberrante de Beth (Archie Goodwin, Barry Smith y Frank Brunner, Marvel Premiere \#4, septiembre de 1972).

En este punto, el curso de los acontecimientos se precipita: los protagonistas, igual que el de «The Shadow Over Innsmouth», se ven acosados por los habitantes infrahumanos de la localidad. Ahora bien, mientras que Stoddar confiesa que se encuentra «bone-marrow scared!» (Marvel Premiere \#4, 1972: 18), Extraño señala que todo lo ocurrido forma parte de una amenaza mayor que deberá afrontar. Nuevamente, comprobamos la oposición entre un personaje de mayores reminiscencias lovecraftianas, como es Stoddar, frente a Extraño que aún se rige por los códigos superheroicos.

De hecho, al final Stoddar sucumbe a la llamada de los habitantes de Starkesboro y asume su condición verdadera: «I'm coming out! becoming that which was ever within me» (Marvel Premiere \#4, 1972: 19). Al cabo, observamos la cercanía del personaje de Ethan Stoddar respecto al protagonista de «The Shadow Over Innsmouth». Ambos reconocen su herencia procedente de las divinidades cósmicas y aceptan su destino al servicio de

18. Como indicaba Robert Harvey: «In comics, space, not time, manipulates pacing and our response» (1996: 177). En este caso, la planificación de las viñetas en el cómic de Extraño está destinada a crear un efecto de suspense. 
aquellas. ${ }^{19}$ En cuanto a Stoddar, se pone al mando de los engendros que pueblan Starkesboro y logra apresar a un Strange debilitado. El número de Marvel Premiere acaba con un cliffhanger, recurso derivado de la forma serial de este medio, pues nos presenta a Extraño encadenado y rodeado por los pobladores de Starkesboro, ahora comandados por Stoddar. Este, cuyos rasgos y modo de expresarse revelan su nueva condición híbrida, ordena que sus acólitos abran «the door to the labyrinth» (Marvel Premiere \#4, 1972: 21).

Los siguientes números de Marvel Premiere prosiguen este arco argumental, centrándose en una serie de enfrentamientos mágicos entre Extraño y varios de los servidores de Shuma-Gorath. Estos se presentan como una suerte de trasuntos de algunos de los seres que conforman los Mythos; así, Sligguth, N'Gabthoth y Dagoth recuerdan a las criaturas conocidas respectivamente como Yig, Cthulhu y Dagón respectivamente (figura 5). Estos números, que presentan equipos creativos diferentes al que hemos analizado arriba, siguen con mayor intensidad las formas de la fantasía superheroica, mostrando combates épicos entre Extraño y las huestes de Shuma-Gorath.

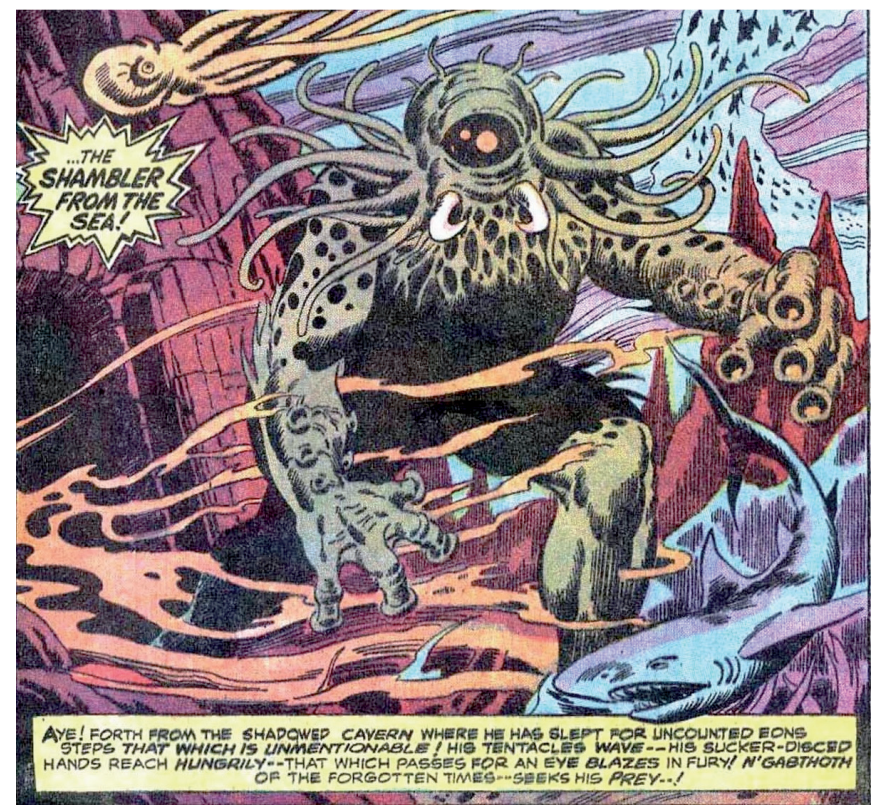

Figura 5. La versión Marvel de Cthulhu (Gardner Fox y Mike Ploog, Marvel Premiere \#6, enero de 1973).

19. Tal y como confiesa el protagonista de «La sombra sobre Innsmouth»: «No podría sustraerme a mi destino. Sería inmortal y viviría para siempre con aquellos que ya existían cuando el hombre aún no había aparecido sobre la faz de la tierra» (Lovecraft, 2001: 300). 
Como colofón a nuestro análisis, optamos por examinar un pasaje perteneciente al Marvel Premiere \#7 (marzo de 1973) titulado «The Shadows of the Starstone!». Esto se debe a que, junto al ejemplar revisado previamente, dicha historieta presenta una mayor conexión con la fuente lovecraftiana que el resto de comic books de la saga de Shuma-Gorath. ${ }^{20}$ En un momento dado de este número, las aventuras de Stephen Strange se interrumpen para presentarnos a un tal Henry Gordon, quien camina por la ciudad ficticia de Penmallow. De la misma forma que ocurrió con los personajes de Keneth Ward y Ethan Stoddar, advertimos el empleo de una figura ajena al universo del Doctor Extraño, que va a experimentar el horror de una forma no muy distinta a la de los protagonistas de los relatos lovecraftianos.

Gordon se dirige a la residencia que ha heredado de su tío, un cartel de apoyo nos muestra el tono que va a caracterizar este episodio: «Lightining crackles ominously in a darkly threatening sky and thunder rumbles to his every step as Henry Gordon walks the lonely moor» (Marvel Premiere \#7, 1973: 4). Por su parte, un globo de pensamiento vincula las sensaciones de Gordon a esas circunstancias: «This place gives me the creeps» (Marvel Premiere \#7, 1973: 4). Ya en la casa, Henry Gordon conoce a la antigua ama de llaves, quien le advierte que su tío se dedicó a amasar un amplio conocimiento «of the occult arts, of the older wisdoms of magic and necromancy» (Marvel Premiere\#7, 1973: 6). Como no podía ser menos, este personaje terminará enfrascado en la extraña colección de libros de su tío, que comprende volúmenes como Los cultos innombrables de Von Juntz. ${ }^{21}$ Una de las viñetas muestra un primer plano de Gordon sudoroso y completamente impresionado por sus lecturas. El dibujo manifiesta una estética que puede recordarnos a los cómics de terror de la editorial EC (Figura 6). En conjunto, evidenciamos el esfuerzo por trasladar al cómic un motivo tan común en las narraciones del horror cósmico.

A partir de aquí, Gordon se obsesiona con los contenidos de dichos volúmenes, entre ellos las referencias una ciudad hundida llamada Kalumesh. $\mathrm{Al}$ parecer, esta urbe «abandonada a un culto maligno» fue sumergida por «los antiguos que adoraban el bien». En este caso, la historieta parece referen-

20. Seguimos la versión española de dicho cómic incluido en el octavo volumen de la colección Biblioteca Marvel: Doctor Extraño (2004: 127-146). En cuanto al equipo que elaboró el Marvel Premiere \#7, lo conformaban: Gardner Fox al guión, Craig Rusell a los lápices y los entintadores Mike Esposito, Frank Giacoia y David Hunt. Como apunte, señalamos que Fox creó en 1940 para DC Comics el personaje conocido como Doctor Fate; posiblemente, el primer pastiche lovecraftiano dentro del mundo del cómic (Jones, 2013).

21. En este sentido, el personaje del cómic analizado, de igual modo que otros individuos creados por Lovecraft, se adecua a las tesis sobre el relato de terror esbozadas por Noel Carroll, quien sostuvo que «the horror story is driven explicitly by curiosity» (Carroll, 1990: 182). 


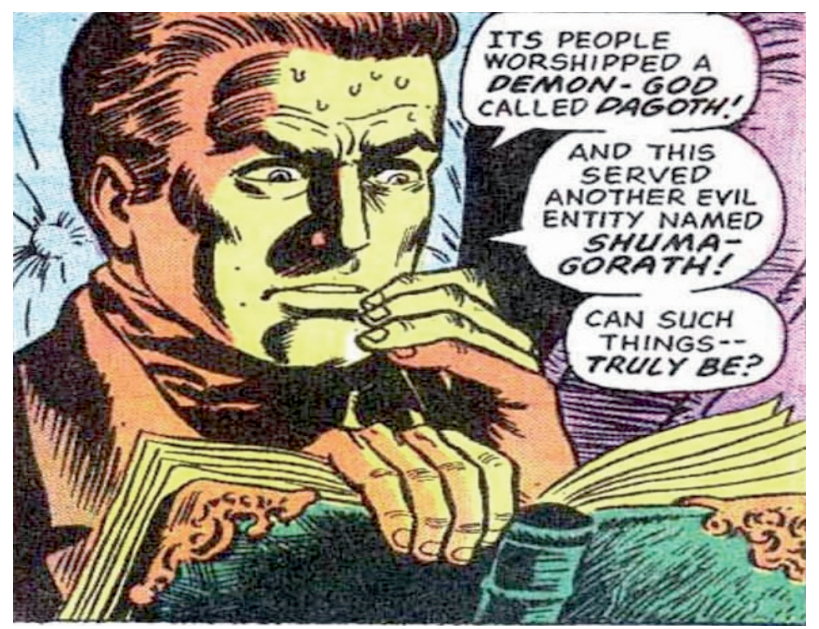

Figura 6. Henry Gordon fascinado por Los cultos innombrables de Von Juntz

(Gardner Fox y Craig Rusell, Marvel Premiere \#7, marzo de 1973)

ciar la clasificación maniquea de los Mythos conformada por August Derleth, quien confrontó a los dioses Arquetípicos con los Primigenios.

Las pesquisas de Henry Gordon le llevan hasta una extraña joya, cuyo tacto se describe frío y «touched by the frigid voids between the stars» (Marvel Premiere \#7, 1973: 7). Los objetos procedentes de otros planos de la realidad que, además, siguen mostrando sus conexiones con sus orígenes suelen resultar comunes dentro de los relatos de índole lovecraftiana. También ocurre con el siguiente motivo, ya examinado en este estudio; nos referimos a la conciencia por parte del personaje de que parece destinado a los sucesos que protagoniza, debido en buena parte a su herencia. El propio Gordon expresa dicha preocupación con un globo de texto: «Have I inherited his evil taint?». Por su parte, la viñeta correspondiente muestra su rostro sudoroso y desquiciado, dentro de una composición en primer plano basada en el claroscuro (Marvel Premiere \#7, 1973: 7).

Por último, el número siete de Marvel Premiere introduce otro tema recurrente dentro del horror cósmico, que permaneció ausente en el cuarto ejemplar de dicha colección, a pesar de su inspiración en «The Shadow Over Innsmouth». En esta ocasión, hablamos del mar como espacio para el terror. ${ }^{22}$

22. Timo Airaksinen (1999) estudió este asunto, relacionando los espacios marítimos y cósmicos como elementos aterrorizantes dentro del imaginario de Lovecraft. Para este autor, las conexiones de estos emplazamientos también se corresponden con la apariencia de la mayoría de los monstruos lovecraftianos. Según Airaksinen: «Lovecraft wants to make the body crustaceous because then he can use an 
Por consiguiente, Gordon decide sumergirse en un lugar del océano, «after an all-night persual of the ancient tomes of his uncle's library» (Marvel Premiere \#7, 1973: 7). Finalmente, este personaje no solo contemplará la ciudad hundida de Kalumesh, sino que despertará al propio Dagoth.

\section{CONCLUSIONES}

A lo largo de estas páginas, hemos tratado de examinar el influjo de la fantasía basada en el horror cósmico articulado por Lovecraft y su círculo dentro del universo superheroico de los cómics producidos por Marvel. Esta editorial norteamericana siempre ha mantenido un estrecho contacto con la realidad cultural de su contexto, por lo cual la influyente narrativa del autor de Providence no podía resultar una excepción. Más allá de la mera cita y de vagas referencias incorporadas a un gran número de comic books, evidenciamos cómo en la configuración del personaje del Doctor Extraño se encuentran unos esfuerzos apreciables por trasponer al medio secuencial el imaginario de los Mythos. Este pormenor se debe a que las particularidades del Hechicero Supremo, ligado al mundo de la magia, facilitan este proceso por encima de otras figuras de la compañía más ligadas a las singularidades del superhéroe.

En este sentido, la mayor parte de nuestro trabajo ha consistido en analizar de forma pormenorizada un ejemplo que consideramos paradigmático: la saga sobre el engendro creado por Howard, Shuma-Gorath, inserta en la colección Marvel Premiere. Más concretamente, hemos dedicado un mayor espacio al cuarto número de dicha serie por varias razones provechosas. Para empezar, el equipo creativo de dicho cómic albergó una experiencia relevante dentro del cómic de terror, incluyendo el tratamiento de elementos pertenecientes al imaginario lovecraftiano. Por otra parte, el argumento esbozado por Roy Thomas se constituye como una reescritura de «The Shadow Over Innsmouth».

En relación a esto, hemos revisado el tratamiento de motivos diversos vinculados al horror cósmico y su plasmación en las viñetas dibujadas por Barry Smith y Frank Brunner. La estructura y muchos de los temas tratados en «The Spawn of Sligguth» presentan coincidencias notables respecto a su fuente. Así ocurre, a grandes rasgos, con la estructura itinerante del cómic, la presentación monstruosa de los habitantes del lugar erigido como fuente del ho-

allusion to the deep sea, and at the same time to deep space. They come from space, but their horror is that of sea creatures» (1999: 120). 
rror o la identificación final del protagonista con estos últimos. Asimismo, observamos los esfuerzos de los autores del cómic por encajar en el Universo Marvel un relato de esta índole. Para tratar de compatibilizar el terror cósmico dentro de la fantasía superheroica, el número analizado se sirve de varios recursos. Por ejemplo, al debilitar las facultades de Extraño, el mago debe afrontar el horror que le aguarda de un modo diferente a la de la mayoría de cómics que protagoniza. Caso similar ocurre con la inclusión de la figura de Ethan Stoddar, todo un trasunto del protagonista del relato original escrito por Lovecraft. Este tipo de personajes, según observamos en otros títulos, sirven para presentar a los lectores a unos individuos que puedan experimentar la sensación del horror de un modo diferente a la de héroes como Stephen Strange.

Ahora bien, el uso de las artes místicas dominadas por Extraño en ocasiones, la distancia por el humor o el recuerdo continuo de que el número correspondiente se encuentra en un universo y una serie concretas nos advierten del ámbito en que nos encontramos. Sin embargo, estos últimos pormenores añaden interés a los fenómenos de reescritura como el que afrontamos y, por supuesto, revelan la vigencia de las creaciones de Lovecraft, capaces de convivir en el mismo universo que Hulk o Magneto.

\section{BIBLIOGRAFÍA}

Adams, Neal, y Roy Thomas (1974): Conan the Barbarian \#37, Marvel Publishing, Nueva York.

Airaksinen, Timo (1999): The Philosophy of H.P. Lovecraft: The Route to Horror, Peter Lang, Nueva York.

Andru, Ross, y Len Wein (1974): Giant-Size Spider-Man \#1, Marvel Publishing, Nueva York.

Bendis, Brian, y Stefano Caselli (2009): Secret Warriors \#2, Marvel Publishing, Nueva York.

Bendis, Brian, y Steve McNiven (2005): The New Avengers \#7, Marvel Publishing, Nueva York.

Blanco, Fernando, John Layman, Fabiano Neves y Sean Phillips (2007): Marvel Zombies Vs. Army of Darkness, Marvel Publishing, Nueva York.

Brunner, Frank, Archie Goodwin, Barry Smith y Roy Thomas (1972): Marvel Premiere \#4, Marvel Publishing, Nueva York.

CARPEnter, John (dir.) (1982): The Thing ( $L a$ cosa), Universal Pictures, Estados Unidos.

Carrol, Noel (1990): The Philosophy of Horror: Or, Paradoxes of the Heart, Routledge, Nueva York.

CARTER, Lin (2001): «H.P. Lovecraft: the books» en Darrel Schweitzer (ed.), Discovering H.P. Lovecraft, Wilside Press, Pennsylvania, pp. 107-147. 
Claremont, Chris, y Dave Cockrum, (1982): Uncanny X-Men \#155, Marvel Publishing, Nueva York.

Сомтог, Pierre (2011): Marvel Comics in the 1970s: an issue by issue field guide to a pop culture phenomenom, TwoMorrows, Raleigh.

Cooke, Jon, y David RoAch (2001): The Warren Companion: The Definitive Compendium to the Great Comics of Warren publishing, Tomorrows Pub, Raleigh.

Corben, Richard (2008): Haunt of Horror: Lovecraft, Marvel Publishing, Nueva York.

Cotter, Robert Michael (2008): The Great Monster Magazines: A Critical Study of the Black and White Publications of the 1950s, 1960 s and 1970s, McFarland \& Company, Jefferson.

Craig, John (1950): The Vault of Horror \#16, Entertaining Comics, Nueva York.

Fox, Gardner, y Craig Rusell (1973): Marvel Premiere \#7, Marvel Publishing, Nueva York.

Geissman, Grant (2005): Foul Play!: The Art and Artists of the Notorious 1950s E.C. Comics, Harper Desing International, Nueva York.

Gil GonzÁlez, Antonio (2013): +Narrativa(s). Intermediaciones novela, cine, cómic y videojuegos en el ámbito hispánico, Ediciones Universidad de Salamanca, Salamanca.

Harvey, Robert (1996): The Art of the Comic Book: An Aesthetic History, University Press of Mississippi, Jackson.

Herron, Don (2000): «The Dark Barbarian», en Don Herron (ed.), The Dark Barbarian: The Writings of Robert E Howard, a Critical Anthology, Wilside Press, Nueva Jersey, pp. 149-182.

Нiтснсоск, Alfred (dir.) (1960): Psycho (Psicosis), Shamley Productions, Estados Unidos.

JoNES, Mark (2013): «Lovecrafian being in popular culture», en David Simmons (ed.), New Critical Essays on H.P. Lovecraft, Palgrave Mcmillan, Nueva York.

LeE, Stan, y Diтко, Steve (1963): Strange Tales \#110, Marvel Publishing, Nueva York.

Llopis, Rafael (2001): «Los mitos de Cthulhu», en Rafael Llopis (ed.), Los mitos de Cthulhu. H.P. Lovecraft y otros, Alianza Editorial, Madrid, pp. 11-52.

Lovecraft, Howard Phillips (1984): «La sombra sobre Innsmouth», en Rafael Llopis (ed.), Los mitos de Cthulhu. H.P. Lovecraft y otros, trad. Francisco Torres Oliver, Alianza Editorial, Madrid, pp. 223-300.

(1984): El horror en la literatura, Alianza Editorial, Madrid.

Maroto, Esteban, y Roy Thomas, Roy (2000): H.P. Lovecraft's The Return of Cthulhu \#1, Cross Plains Comics, Nueva York.

Marín, Rafael (2016): Marvel: crónica de una época, Dolmen Editorial, Palma de Mallorca.

Mitchell, Charles (2001): The Complete H.P. Lovecraft Filmography, Greenwood Press, Connecticut.

Nyberg, Amy Kiste (1998): Seal of Aproval. The History of the Comics Code, University Press of Mississippi, Jackson.

Pérez Bowie, José Antonio (2010): Reescrituras fílmicas nuevos territorios de la adaptación, Ediciones Universidad de Salamanca, Salamanca. 
RaImI, Sam (dir.) (1981): Evil Dead (Posesión infernal), Renaissance Pictures, Estados Unidos.

RApHAel, Jordan, y Tom Spurgeon (2003): Stan Lee and the Rise and Fall of the American Comic Book, Chicago Review Press, Chicago.

Ringel, Faye (2014): «I Am Providence: H. P. Lovecraft», en Charles Crow (ed.), A Companion to American Gothic, John Wiley \& Sons Inc, Hoboken.

RoAs, David (2001): «La amenaza de lo fantástico», en David Roas (ed.), Teorías de lo fantástico, Arco/Libros, Madrid, pp. 7-44.

Santos Castillo, Alberto (2016): «Introducción», en Howard Phillips Lovecraft, La sombra sobre Innsmouth, Edaf, Madrid.

ScotT, Ridley (dir.) (1979): Alien (Alien el octavo pasajero), 20th Century-Fox, Estados Unidos.

Sмiтh, Don (2006): H.P. Lovecraft in Popular Culture: The Works and Their Adaptations in Film, Television, Comics, Music and Games, McFarland \& Company, Jefferson.

STEINER, Bernd (2005): H. P. Lovecraft and the Literature of the Fantastic: Explorations in a Literary Genre, Grin Verlag, Norderstedt.

VVAA (2000): Los Defensores: el nacimiento de los defensores, trad. José María Méndez, Fórum, Barcelona.

Zunzunegui, Santos (2007): Pensar la imagen, Cátedra, Madrid. 


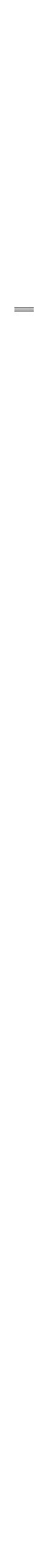

